\title{
John Airey*
}

\section{The Ability of Students to Explain Science Concepts in Two Languages}

\begin{abstract}
This paper analyses the ability of twenty-one physics undergraduates at two Swedish universities to orally describe and explain in both Swedish and English the science concepts met in their lectures. This ability is related back to the language used to teach the concepts (English, Swedish or both languages). Transcripts of student descriptions in both languages are rated using three measures:

1. Fluency (in terms of syllables per second and mean length of runs)

2. Code-switching

3. A judgment about the 'disciplinarity' of what is said.

Comparison between languages finds that students speak on average 45\% slower and have 33\% shorter runs in their English descriptions. However, these differences in speaking rate and run length become much lower (28\% and 26\% respectively) in those transcripts where students appear to have adequately understood the concepts that were presented in the lectures. These latter values are in line with findings in comparative studies of other types of speech event (See Hincks 2010). Analysis of code-switching identifies some students $(n=3)$ who have great difficulty describing disciplinary concepts in English. These were first year students and were being taught in English for the first time. It is thus concluded that for some students disciplinary English is indeed a problem. However, from a disciplinary point of view, all other students give similarly good (or bad) descriptions of physics concepts in both Swedish and English, regardless of the language used in the lectures.
\end{abstract}

\section{Introduction}

In the British Council report, English Next, Graddol (2006) documents the growth of English as a lingua franca (ELF). As Graddol points out, communication in English is now much more likely to be between two non-native speakers than between two native speakers of English. The main tenet of ELF is that English has become a truly international language, and native speakers can thus no longer claim to be the sole arbiters of the way the English language may, or may not, be used. ELF has received a great deal of attention in research circles, with researchers interested in documenting this 'new' form of English and discussing the linguistic rights of non-native speakers (e.g. Ammon 2000; Björkman 2008a, 2008b; Firth 1996; Jenkins 2007; Mauranen/Ranta 2008; Seidlhofer 2004; Shaw 2008; Smit 2007). This interest is of particular relevance in a higher education context, since more and more courses are being taught through the medium of English (e.g. Maiworm/Wächter 2002; Wächter/Maiworm 2008). However, little research has been carried out into the effects on disciplinary learning of an ELF approach to higher education.

This lack of research means there is much we do not yet know about teaching in English. For example, what happens when non-native university students are taught in English? Do students taught in L2 learn their subject as well as if they were taught in L1? If non-native students are taught in English can they access and use the knowledge they acquire in L1? These are some of the questions that are currently being asked in the higher education community.

This paper analyses the ability of twenty-one undergraduate physics students at two Swedish universities to orally describe and explain in both Swedish and English the science concepts they

\footnotetext{
* John Airey

Linnceus University

School of Languages and Literature

SE-391 82 Kalmar

John.Airey@Inu.se
}

\author{
Stockholm University \\ Department of Education in Languages and \\ Language Development \\ SE-106 91 Stockholm
}


have encountered in L1 and L2 lectures. The aim of this analysis is to give us an insight into the processes at work when students attend lectures in a second language.

\section{Research background}

Be it in the first or a second language, researchers from various disciplines and research traditions have observed that students find the specialist discourse of disciplines particularly impenetrable (e.g. Airey/Linder 2009; Bourdieu et al. 1965/1994; Englund 1998; Geisler 1994; Lemke 1990; Middendorf/Pace 2004; Northedge 2002; Östman 1998; Roth et al. 1997; Säljö 2000; Wickman/ Östman 2002). Geisler (1994: xi-xii) summarizes the complexity of this problem in the L1 context, observing that disciplinary discourse appears to "[...] afford and sustain both expert and naïve representations: the expert representation available to insiders to the academic professions and the naïve representation available to those outside".

If such problems exist in L1 lectures, what, then, can we say about the L2 lecture? Airey/Linder (2006: 599) suggest that "[...] changing the lecturing language merely accentuates communication problems that are already present in first-language lectures". If this is the case, then we can hypothesise that students will learn less effectively in L2. Despite the apparent logic of this argument, the small amount of research carried out in this area actually points to strong student adaptation effects when university lectures are taught in L2. For many students this adaptation appears to override any negative language effects of being taught in L2.

It is thus difficult to isolate the effects of teaching language on disciplinary learning. Despite this problem there are a small number of international studies that claim to have found measurable effects of teaching in a second language on disciplinary learning at tertiary level. Researchers in New Zealand for example, report negative correlations between second-language learning and performance in undergraduate mathematics, with Samoan students disadvantaged by $10 \%$ when taught in a second language (Barton/Neville-Barton 2003, 2004; Neville-Barton/Barton 2005). These negative effects were found to be at their worst in the final undergraduate year. Similar relationships have been found by Gerber et al. (2005) in their study of speakers of Afrikaans learning undergraduate mathematics in English in South Africa. Research in the Netherlands has also identified negative effects for Dutch engineering students' learning when they are taught in English (Klaassen 2001; Vinke 1995). However, the longitudinal nature of Klaassen's work led to an interesting result. After one year of study there were no longer any measurable differences in engineering grades between research and control groups - as suggested above, students had adapted to being taught in English. Building on this work, Airey/Linder $(2006,2007)$ showed that, when asked directly, students believed that the teaching language had little effect on their learning. However, the same students could point out a number of significant differences in their learning when they were asked to comment on video footage of lectures they had attended. The differences found involved the amount of interaction in lectures (students asked and answered fewer questions when taught in English) and a greater focus on the process of note-taking in English-medium teaching at the expense of following the lecturer's line of reasoning. Furthermore, the students in the study changed their learning strategies to cope with the language shift in a number of ways: students read sections of work before lectures, asked questions after the lecture or simply no longer took notes in class. However, in some extreme cases lectures had simply become sessions for mechanical note taking with extra work devoted to making sense of these notes later.

Airey/Linder's work documents the ways in which students change their learning patterns in order to adapt to being taught in English, but one question remains: Can such student adaptation fully compensate for the change in teaching language, or are there residual negative effects on disciplinary learning when students are taught in L2? The analysis presented in this paper attempts to answer this question by comparing the ability of students to describe and explain disciplinary concepts they have met in lectures taught in English and Swedish. 


\section{Method}

The 58 student transcripts analysed in this article are taken from three case studies (Airey 2009b). The first data set comes from interviews with five, second-year students at a larger, researchbased university. These students were reading two parallel monolingual courses: Electromagnetism taught in English, and Mathematical Methods for Physics taught in Swedish. The second data set is sourced from interviews with three first-year students at a smaller, teaching-based university. These students were also reading two parallel monolingual courses: Classical Mechanics in English and Oscillations and Waves in Swedish. Finally, the third data set comes from interviews with thirteen students at the original larger, research-based university. Unusually, this final group of students were reading a single bilingual course in Quantum Physics. While their morning lectures were taught in English (due to the presence of exchange students), students were taught in Swedish in the afternoon (because the exchange students were then in another group). The data sources for the three studies are summarized in Table 1 below:

\begin{tabular}{lc|c|c} 
& Case study 1 & Case study 2 & Case study 3 \\
\cline { 2 - 4 } $\begin{array}{l}\text { Number of } \\
\text { Students }\end{array}$ & 5 & 3 & 13 \\
$\begin{array}{l}\text { Undergraduate } \\
\text { Year }\end{array}$ & Second year & First year & First year \\
$\begin{array}{l}\text { Course taught in } \\
\text { English }\end{array}$ & Electromagnetism & $\begin{array}{c}\text { Classical } \\
\text { Mechanics }\end{array}$ & $\begin{array}{c}\text { Quantum } \\
\text { Physics* }\end{array}$ \\
$\begin{array}{l}\text { Course taught in } \\
\text { Swedish }\end{array}$ & $\begin{array}{c}\text { Mathematical } \\
\text { Methods for } \\
\text { Physics }\end{array}$ & $\begin{array}{c}\text { Oscillations and } \\
\text { Waves }\end{array}$ & \\
\cline { 2 - 4 } & \multicolumn{2}{|c}{}
\end{tabular}

Table 1. Overview of data sources for the three studies

*Denotes a bilingual course taught by the same teacher to the students in both languages

The choice of the specific situations these case studies examine was made pragmatically, based on the availability of courses where the same students were taught in English and Swedish.

\subsection{Data collection and analysis}

In total, six lectures were videoed (Three in English and three in Swedish). Each student was then interviewed individually using short sections of the two lectures that the student had attended in a process of stimulated recall (Calderhead 1981). Students were asked to describe and explain the physics concepts dealt with in the clips. These descriptions were elicited in both English and Swedish, with other questions inserted as distracters between the two descriptions. The student descriptions were digitally recorded and transcribed verbatim.

Transcriptions were analysed qualitatively in terms of three parameters: disciplinarity, codeswitching, and fluency. The latter was judged in terms of speaking rate, measured in syllables per second, and mean length of runs measured in syllables.

\subsubsection{Disciplinarity}

In order for the transcripts to be appropriately assessed, a judgement needed to be made about what the students said from a disciplinary point of view. This is important since it is conceivable that a description that appears fluent from a linguistic point of view may, in fact, reveal disciplinary errors or alternative conceptions. Table 2 below was therefore developed as a guide when coding the transcripts for disciplinarity. The coding of all transcripts was carried out by the same physics teacher. 


\begin{tabular}{|c|c|c|}
\hline Grade & Label & Descriptor \\
\hline 1. & Weak: & Student uses very little disciplinary language. \\
\hline 2. & Intermediate: & $\begin{array}{l}\text { Student uses some disciplinary terms appropriately, } \\
\text { but either has clear disciplinary lexical gaps or uses } \\
\text { other terms inappropriately. }\end{array}$ \\
\hline 3. & Good: & $\begin{array}{l}\text { Student uses disciplinary terms appropriately in the } \\
\text { sequence, but does not develop ideas fully. }\end{array}$ \\
\hline 4. & Excellent: & $\begin{array}{l}\text { Student uses disciplinary terms appropriately and } \\
\text { develops ideas fully. Expert explanation. }\end{array}$ \\
\hline
\end{tabular}

Table 2. 1-4 scale of descriptors used for classifying transcripts in terms of disciplinarity

\subsubsection{Code-switching}

Where two languages are involved, lexical gaps may also be filled by code-switching (i.e., inserting a word or phrase from another language). For the purposes of the analysis presented here, the notion of involuntary code-switching is adopted to characterize a situation where code-switching occurs in a monolingual setting. In the interviews described earlier, students were instructed to use one language exclusively for a given description. Any code-switching that occurred was thus deemed involuntary and indicative of a lexical gap in the language being spoken.

\subsubsection{Fluency}

There are a number of methods for assessing speaking ability that can be employed in order to estimate the fluency of speech. The majority of these methods assume a connection between speech rate and degree of control of a language. This is because higher speech rate is seen as an indicator that knowledge has become proceduralized (Anderson 1982). The most basic parameter calculated in linguistic studies is words per minute (WPM) - this method has the benefit of being easily recognisable to most readers as a well-established measure of typing speed. However, Hincks (2005) points out that when comparing speech rate between languages it may be more appropriate to use syllables per second (SPS) rather than WPM. This is because average word length can vary significantly between languages. Another related method used in linguistics involves documenting pauses. Chambers (1997) suggests there will be a difference between first and second language speech with regard to the frequency of pauses, since pauses may indicate lexical gaps in the second language. Thus, a number of studies have claimed that the most statistically significant measure of speaking ability is the amount of speech uttered between pauses (Kormos/Dénes 2004; Towell et al. 1996). This approach involves calculating the average phrase length in syllables. In the literature, this value is termed mean length of runs (MLR). Incidentally, MLR is also better suited to interview situations like the ones described in this article since it eliminates the need to isolate and calculate the total speaking time for a given individual. For interviews, this process often involves locating and deleting interviewer speech and correcting the speaking time accordingly.

Hincks $(2005,2010)$ compared presentations on the same topic given by the same students in English and Swedish using the SPS and MLR measures. Her main finding is that when Swedish students speak English they pause more often, use shorter phrase lengths and speak on average 23\% slower. However, Hincks advises caution when comparing speaking ability between students based on SPS and MLR, pointing out that there is a strong effect of individual speaking style which carries over from a student's first language to their second-language use. Students who speak slowly with frequent pauses in their first language show a similar pattern in their second- 
language speech. Thus, any attempt to compare scientific literacy between students using MLR or SPS methods will need to account for individual differences in speaking patterns in some way.

Hincks (2010) found that in the majority of studies the length of time used to designate a pause varies between 200 and 300 milliseconds. The analysis presented in this article takes a different approach, using a qualitative rather than quantitative assessment of pauses. Hence, in this article, only those pauses that are experienced as such by a listener are recorded. Whilst this method obviously makes comparison with earlier work problematic, it is argued that it provides a more accurate measure of scientific literacy - trading as it does reliability for validity. The method also goes some way to taking into account the problem of variation in student speech patterns noted by Hincks. Analysis of a short transcript from the data set used in this article showed that this qualitative method appears to consistently designate as pauses everything over 400 milliseconds, with the minimum length that was noticed as a pause being at around 250 milliseconds.

The method used in this article to determine the speaking rate (SPS) and mean length of runs (MLR) for the 58 transcripts can be found in (Airey 2009a). An example of the application of this approach is given in the appendix.

\section{Results}

The combined data from the three case studies can be seen in Table 3. Each of the case studies forms one of the three major rows of the table. In the original data set (Airey, 2009b) each student was assigned a pseudonym from A-W. These pseudonyms have been retained for this article since they aid reference to particular data sets. After the pseudonyms, the next column details the teaching language used in the courses the students attended (two monolingual courses in English and Swedish for cases 1 and 2 and a single bilingual course for case 3). The remainder of the table consists of two major columns detailing the results of the analysis of the 58 transcripts. The first major column reports the syllables per second, mean length of runs, amount of code-switching and the disciplinarity rating for student descriptions in English. The remaining column reports the corresponding values for student descriptions in Swedish. 


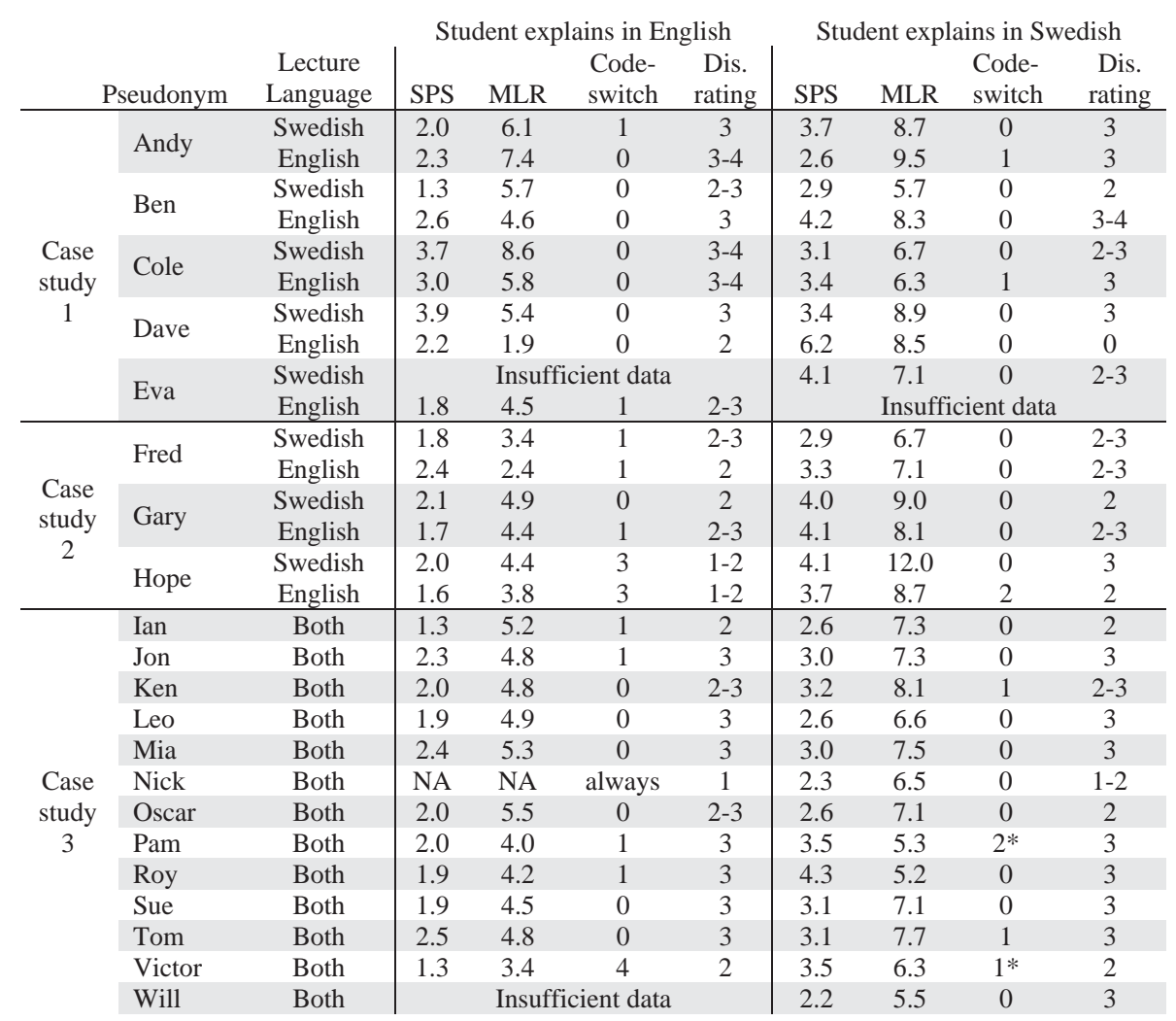

Table 3. Overview of the analysis of all 58 transcripts of student descriptions of science concepts with respect to the language used to teach the concept. The data is presented in terms of four parameters: syllables per second (SPS), mean length of runs (MLR), code-switching and disciplinarity.

*Denotes code-switching where the student immediately corrects in the appropriate code.

Interpretation of the data presented in table 3 is discussed in the next section using the three parameters described earlier, i.e. disciplinarity, code-switching, and fluency (measured in terms of SPS and MLR values).

\section{Analysis and discussion}

In this section the quality of the student descriptions of physics concepts in Swedish and English is discussed in terms of the parameters collated in Table 3 and related to the language used to teach the concept.

\subsection{Disciplinarity}

The student descriptions were judged from a physics perspective using the disciplinarity scale described earlier. The first point that can be noted when examining the disciplinarity ratings in Table 3 is that second-year students have generally higher ratings than first-year students. Three of the five students in study 1 achieve the rating 3-4 for at least one of their descriptions. By comparison, none of the first-year students achieve this rating, and in fact, two of the first-year students (Hope and Nick) have transcripts that are graded 1-2 or lower. This finding is in full agreement with Wickman/Östman's (2002) view of disciplinary learning as a gradual socialization into a disciplinary discourse.

Turning now to Hope's descriptions, we can see that when taught in Swedish, the disciplinarity of her Swedish description is good (grade 3) but the corresponding English description of the same concept is very weak (grade 1-2). Clearly, Hope's ability to describe disciplinary concepts 
in English is severely hampered by her inability to speak disciplinary English. We can therefore conclude that disciplinary English causes problems for some students. From this data set it is not possible to see whether such problems are solely a product of not being able to speak disciplinary English (i.e. a generative effect) or whether students also have problems following in lectures (i.e. an interpretive effect).

Disregarding the two students who have severe problems with English, there is strong agreement between student disciplinarity ratings in both languages - any difference being within a half a grade point, with the 'better' description just as likely to be in English as in Swedish ${ }^{1}$. It is therefore concluded that, above an initial threshold of competence in disciplinary English, students give descriptions with similar levels of disciplinarity in both English and Swedish, regardless of the language used to teach them.

There is one notable (and initially puzzling) exception to this general rule - Cole gives a much better description in English of a concept that was taught in Swedish. However, closer examination of the full transcript and sound file showed that Cole actually gave expressions of starting to understand what the lecturer was trying to explain during the stimulated recall clip that was shown between the two descriptions - i.e. he learned something in the short period between his two descriptions. This can also be seen in the transcript where, when asked to describe the concept in English after watching a Swedish lecture clip he starts his description with, "Well, as he just said ...”.

\subsection{Code-switching}

The first point that should be highlighted from the data in Table 3 is that two students (Hope \& Nick) find it almost impossible to speak about disciplinary concepts in English (see also the discussion of disciplinarity above). In Nick's case he was in fact unable to use English at all in his descriptions of physics concepts, code-switching immediately and permanently to Swedish. English descriptions are also a problem for Victor, who code-switched extensively to Swedish disciplinary vocabulary. These three students were all in their first year of study, and had not been taught in English before. Interestingly, these same students encountered few problems when talking about their background in English at the start of their interviews, and thus it is concluded that it is precisely control of disciplinary English that is lacking. In the example below, Victor does not have access to the disciplinary terms: number, squared, and imaginary:

\footnotetext{
I didn’t understand why it wasn't a real ... er vad ska jag saga? Tal - er only when you har det upphöjd till två. But she said it was an imeg...imag - ett sånt där tal.
}

[Translation: I didn't understand why it wasn't a real ... er what should I say? Number - er only when you have it squared. But she said it was an imeg...imag - one of those numbers.]

Such code-switching was not unusual when first-year students described physics concepts in English, and it was noticeable that these students' lexical gaps in disciplinary English may cause a breakdown in communication. For example, the student in the interview excerpt below uses the false friend ${ }^{2}$ feather instead of the word spring:

Yeah, yeah. I think it's a feather, that's ... it’s going from potential energy to kinetic energy and if you combine, yeah, that with the feather constant you get this [...]

In comparison, the second-year students (case study 1) rarely code-switch in either language. Thus we can conclude that some students find it difficult to use disciplinary English without codeswitching, and that this problem may be something that decreases over time. Clearly the data an-

1 Note: Dave's disciplinarity grade of zero in Swedish does not contravene this description - zero denotes a meta description which was unable to be graded for disciplinarity.

2 A false friend is a word in a second language that resembles a word in a student's first language, but that has a different meaning in the second language. In this case, Swedish has one word, fjäder that means both feather and spring. 
alysed for this article cannot give conclusive results in this area - this would require a longitudinal study.

As might be expected, students code-switch to a much lesser extent in their L1 (Swedish) descriptions of disciplinary concepts. One clear pattern that can be seen in the data is that codeswitching in Swedish L1 descriptions only occurs when English has been used in the teaching of the concept being described.

All code-switching in Swedish was considered to be unlikely to cause a breakdown in communication. There are two reasons for this assertion: first, the lexical gaps were less likely to be central to an understanding of the text. Second, since students are speaking Swedish, it is more than likely that the listener will understand the code-switched (English) word or phrase. Clearly this second assumption about the listener cannot be made when students describe disciplinary concepts in English. Below is an example of this type of first-language code-switching (codeswitched words in bold):

\footnotetext{
Ja, ja den betyder ju, att the curl of $\mathbf{E}$ då är, är minus derivatorn av B fältet men sen just vad en curl är det har man fortfarande inte riktigt fått en så här direkt in, intuitivt, bild av det.

[Translation: Yes, yes it means that the curl of $\mathbf{E}$ there is minus the derivative of the B field, but then exactly what a curl is I've still not really got a, you know direct in, intuitive picture of it.]
}

It is argued that the majority of Swedish physics students would probably not even notice that code-switching had occurred in this description, with curl being perhaps more likely to be used than the Swedish equivalent rotation in student disciplinary descriptions in Swedish.

\subsection{Fluency measures}

The fluency of the student descriptions was judged using measures of syllables per second (SPS) and mean length of run (MLR). The aggregated MLR and SPS values calculated for the three cases can be seen in Table 4.

\begin{tabular}{cccc|ccc} 
& \multicolumn{3}{c|}{ Syllables per } & \multicolumn{3}{c}{ Mean Length of } \\
& English & Swedish & Slower & English & Swedish & Shorter \\
Case 1: $\left(2^{\text {nd }}\right.$ year ML) & 2.5 & 5.7 & $56 \%$ & 5.6 & 7.7 & $27 \%$ \\
Case 2: (1 $1^{\text {st }}$ year ML) & 1.9 & 3.7 & $49 \%$ & 3.9 & 7.4 & $53 \%$ \\
Case 3: (1 $1^{\text {st }}$ year BL) & 2.0 & 3.0 & $33 \%$ & 4.7 & 6.7 & $30 \%$ \\
\hline All students & 2.2 & 4.0 & $45 \%$ & 4.8 & 7.2 & $33 \%$ \\
\hline
\end{tabular}

Table 4. Comparison of fluency measures for student descriptions in English and Swedish across the three cases. Mean values and percentage differences between languages. ML denotes monolingual lectures, $B L$ denotes bilingual lectures

The first point to note from Table 4 is that SPS and MLR clearly measure different things. For the same transcripts, case 1 comes out as the least fluent on the SPS measure, but the most fluent on the MLR measure! This is where the measures of disciplinarity and code-switching become useful. Taking these other measures into account we can clearly see that the transcripts from case 1 are indeed more fluent and thus we can concur with Kormos/Dénes (2004) and Towell et al. (1996) that MLR is indeed the more valid measure.

As can be seen from Table 4, students spoke on average 45\% slower in their English descriptions and had 33\% shorter runs. This represents a much greater difference between English and Swedish speech than that found by Hincks $(2005,2010)$ who reports Swedish students speak on average 23\% slower in English in their oral presentations. This finding is perhaps in line with what could have been expected. The speech events examined in this article were not planned pres- 
entations, but rather situations where students were 'put on the spot' and asked to explain concepts that they had recently encountered in their lectures. It is therefore reasonable to hypothesise that students will have to spend more time to think about what they are going to say. Of course, this will result in slower speech in both languages - however, this process seems to take the students longer when speaking English. There are thus two factors at work which may account for the slower speech found in this study compared to Hincks' earlier work: the differences in the type of speech event (interviews vs. oral presentation) and the student familiarity with and understanding of the material they are talking about.

An attempt to distinguish between these two factors is reported in Table 5, below.

\begin{tabular}{ccc|ccc}
\multicolumn{3}{c|}{ Syllables per } & \multicolumn{3}{c}{ Mean Length of } \\
Second (SPS) & & \multicolumn{3}{c}{ Runs (MLR) } \\
\hline English & Swedish & Slower & English & Swedish & Shorter \\
2.4 & 3.3 & $28 \%$ & 5.2 & 7.1 & $26 \%$ \\
\hline
\end{tabular}

Table 5. Fluency measures for descriptions rated 3 or higher for disciplinarity ( $\mathrm{n}=26)$. Mean values and percentage differences between languages

In Table 5, only those transcripts where the students appear to have understood the concepts that were taught in the lectures are analysed $(n=26)$. This is achieved by selecting transcripts rated 3 or above on the disciplinarity scale. When this is done, the differences in SPS and MLR scores between the Swedish and English descriptions of the same concept are much lower, 28\% and 26\% respectively, which is in much better agreement with Hincks' earlier work. This means that even when students have understood a concept they still speak more slowly and have shorter 'bursts' of speech in their English descriptions. From a methodological point of view one can argue that any residual differences between the values reported in Table 5 and those of earlier studies (See Hincks 2010) are due to the differences in the type of speech event (interview vs. oral presentation).

One of the expressed goals of this article was to examine student fluency as a function of the teaching language. This analysis can only be carried out for case studies 1 and 2 since in case study 3 students were taught a single course in both languages. Moreover, in case study 1 Eva does not have comparable data and, as discussed earlier, Dave gave expressions of learning during the interview process, which invalidates the use of his descriptions. This leaves us with only six students who have the necessary four comparable transcripts. The results of the analysis of this limited data set with respect to teaching language are presented in Table 6 below:

\begin{tabular}{cccc|ccc} 
& \multicolumn{3}{c|}{ Syllables per } & \multicolumn{3}{c}{ Mean Length of } \\
& \multicolumn{3}{c}{ Second (SPS) } & \multicolumn{3}{c}{ Runs (MLR) } \\
\cline { 2 - 7 } English & Swedish & Slower & English & Swedish & Shorter \\
Taught in English & 2.3 & 3.6 & $36 \%$ & 4.7 & 8.0 & $41 \%$ \\
Taught in Swedish & 2.2 & 3.5 & $37 \%$ & 5.5 & 8.1 & $32 \%$ \\
\hline
\end{tabular}

Table 6. Comparison of SPS and MLR values for student descriptions of physics concepts as a function of the teaching language (six students)

Table 6 shows striking similarities between the SPS values for descriptions in English and descriptions in Swedish across the two teaching languages. The MLR values for Swedish descriptions are also very similar, whichever language is used to teach the original concept. However, the MLR values for concepts described in English show a clear difference when students are taught in English or Swedish - in favour of Swedish. This is potentially important since the analysis of Table 4 above suggested that MLR was a more reliable measure of student fluency. It is difficult to envisage a situation where students taught in Swedish would give better descriptions of disci- 
plinary concepts in English unless their understanding of the lecture was better when they were taught in Swedish. It is somewhat puzzling however, that this better understanding when taught in Swedish does not have a corresponding effect on the Swedish MLR values. With a larger data set it would have been possible to analyse only those transcripts where students had clearly understood the disciplinary concept (as was done across the three cases in Table 5). If the differences then disappeared this would suggest that this was indeed an effect of poorer understanding in English.

In summary, then, the analysis of fluency measures for the student descriptions yielded the following results: First, MLR seems to be a more valid measure of the fluency of a student description than SPS. Second, using the whole data set, students speak $45 \%$ slower in their descriptions in English and have 33\% shorter runs, but these values fall to 28\% and 26\% respectively, when selectively analysing only those transcripts where students appeared to have understood the concept they are describing. Finally, analysis of 24 transcripts with respect to teaching language suggests that students have similar speaking rates in their descriptions regardless of the language used to teach a concept. The mean length of runs for Swedish descriptions also appears to be independent of teaching language, however, a difference was found in the MLR of English descriptions in favour of being taught in Swedish.

\subsection{Summary of findings}

The aim of this study was to gain an insight into the processes at work when students attend lectures in a second language. In this respect the following eight findings can be reported:

1. Disciplinary English does indeed cause serious problems for some students.

2. Some (first-year) students find it difficult to describe disciplinary concepts in English without code-switching, however, this may be something that reduces over time.

3. Second-year students give much better disciplinary descriptions than first-year students in both languages.

4. Code-switching in Swedish L1 descriptions only occurs when English has been used in the teaching of the concept being described.

5. Above an initial lower threshold of competence in disciplinary English, students give descriptions with similar levels of disciplinarity in both English and Swedish, regardless of the language used to teach them.

6. SPS and MLR clearly measure different textual features, with MLR being the more valid measure in terms of mirroring disciplinary language competence.

7. From the point of view of fluency, students spoke on average $45 \%$ slower in their English descriptions and had 33\% shorter runs.

8. When selectively analyzing only transcripts where students had understood a concept, the differences in fluency between English and Swedish descriptions are much lower. Students spoke on average 28\% slower in their English descriptions and had 26\% shorter runs. These values are in agreement with the findings of earlier work.

The following two observations on the above findings should be made:

Regarding findings 1 to 3 it is not possible from this data set to ascertain whether students actually do adapt to being taught in English. There is a high degree of drop out from university physics courses (See Johannsen 2007) and thus it is conceivable that the better descriptions provided by second-year students may be partially explained by poorer students leaving the system.

Note too, that finding 5 does not mean that students learn just as well in English as in Swedish finding 5 only states that students can describe what they have learnt in both languages. This says nothing about the relative effectiveness of the two teaching languages for learning. 


\section{Conclusions}

This paper set out to examine the ability of students to describe and explain physics concepts in Swedish and English. In common with earlier studies, the majority of students in the three cases appear to have adapted to being taught in English, but it is still an open question as to whether all students have this capacity. It seems clear that learning in English does appear to be a problem for some Swedish students, and further research will be needed to determine whether such students adapt over time or leave tertiary education.

That said, it was found that above a lower level of competence in disciplinary English, students give similarly rated descriptions of disciplinary concepts in English or Swedish, regardless of the language used to teach them. At first glance this may be mistakenly taken to suggest that it doesn't matter for the majority of students which language is used to teach them. However, this would be incorrect. Students could, for example, be learning less in English, but this is not something that would be possible to see in this data set. One intriguing finding in this area was the run lengths for student descriptions in English (Table 6). Here, there might just be a hint that students learn less well in English, however the limited number of comparative transcripts available for analysis means that this too will need further research. In a pilot analysis of four of the students in this data set (Airey 2009a) I tentatively suggested that teaching in two languages might have some positive effects for learning in terms of students producing better disciplinary descriptions in both languages. Although this may be the case, this too is something that cannot be seen in the analysis of the full data set presented here.

Linguistically, we can conclude that when the students in this study speak in English about a concept they have understood, they speak more slowly and use shorter runs than when they describe the same concept in Swedish. The magnitude of this difference in speaking rate and run length is very similar to findings in earlier studies. What is new in this study, however, is that some students spoke about concepts they had not adequately understood. In these cases the difference in speaking rate and run length between the two languages increases dramatically. This is perhaps something that could have been predicted, but we now have empirical evidence that this is the case.

So what advice can be given a content lecturer who teaches university courses in English? First, it seems that students probably do adapt quite well to being taught in English, however, this adaptation may take longer and/or be less accomplished for some students. This is clearly something that content teachers should bear in mind. Next, one can wonder about the amount of practice students receive in speaking disciplinary English within their undergraduate degree. An earlier language audit of the formal input on undergraduate physics courses in Sweden (Airey/Linder 2008) identified a lack of opportunity to practice speaking disciplinary English. With this in mind, it is surprising that the students in the three case studies give such good disciplinary descriptions in English. Given the lack of practice, we can speculate that any increase in this factor - and in particular the opportunity to speak physics with the teacher would have a positive effect on the resultant student control of disciplinary language. Finally, when it comes to student speaking it is important to understand that in this and all previous studies, students do speak more slowly in a second language. It is important that this slower speech is not to be mistaken for poorer content knowledge.

\section{References}

Airey, J. 2009a: Estimating bilingual scientific literacy in Sweden. In International Journal of Content and Language Integrated Learning 1(2), 26-35.

Airey, J. 2009b: Science, Language and Literacy. Case Studies of Learning in Swedish University Physics. Acta Universitatis Upsaliensis. Uppsala Dissertations from the Faculty of Science and Technology 81. Uppsala [online]. http:// publications.uu.se/theses/abstract.xsql?dbid=9547

Airey, J./Linder, C. 2006: Language and the experience of learning university physics in Sweden. In European Journal of Physics 27(3), 553-560. 
Airey, J./Linder, C. 2007: Disciplinary learning in a second language: A case study from university physics. In Wilkinson, R/Zegers, V (eds.), Researching Content and Language Integration in Higher Education. Maastricht: Maastricht University Language Centre, 161-171.

Airey, J./Linder, C. 2008: Bilingual scientific literacy? The use of English in Swedish university science programmes. In Nordic Journal of English Studies 7(3), 145-161.

Airey, J./Linder, C. 2009: A disciplinary discourse perspective on university science learning: Achieving fluency in a critical constellation of modes. In Journal of Research in Science Teaching 46(1), 27-49.

Ammon, U. 2000: Towards more fairness in international English: Linguistic rights of non-native speakers? In Phillipson, R. (ed.), Rights in language. London: Lawrence Erlbaum, 111-116.

Anderson, J. 1982: Acquisition of cognitive skill. In Psychological Review 89(4), 369-406.

Barton, B./Neville-Barton, P. 2003: Language Issues in Undergraduate Mathematics: A Report of Two Studies. In New Zealand Journal of Mathematics 32 (Supplementary Issue), 19-28.

Barton, B./Neville-Barton, P. 2004: Undergraduate mathematics learning in English by speakers of other languages. Paper presented to Topic Study Group 25 at the 10th International Congress on Mathematics Education, July, 2004.

Björkman, B. 2008a: English as the lingua franca of engineering: The morphosyntax of academic speech events. In Nordic Journal of English Studies 7(3), 103-122.

Björkman, B. 2008b: So where we are? Spoken lingua franca English at a technical university in Sweden. In English Today 24(2), 35-41.

Bourdieu, P./Passeron, J.-C./De Saint Martin, M. 1965/1994: Academic discourse (Teese, R., Trans.). Sanford CA: Sanford University Press.

Calderhead, J. 1981: Stimulated recall: A method for research on teaching. In British Journal of Educational Psychology 51, 211-217.

Chambers, F. 1997: What do we mean by fluency? In System 25(4), 535-544.

Englund, T. 1998: Teaching as an offer of (discursive) meaning? In Gundem, B/Hopmann, S. (eds.), Didaktik and/or curriculum. An international dialogue. New York: Peter Lang, 215-223.

Firth, A. 1996: The discursive accomplishment of normality: On 'lingua franca' English and conversation analysis. In Journal of Pragmatics 26, 237-259.

Geisler, C. 1994: Academic literacy and the nature of expertise: Reading, writing, and knowing in academic philosophy. Hillsdale, NJ: Erlbaum.

Gerber, A./Engelbrecht, J./Harding, A. 2005: The influence of second language teaching on undergraduate mathematics performance. In Mathematics Education Research Journal 17(3), 3-21.

Graddol, D. 2006: English Next [online]. http://www.britishcouncil.org/learning-research-englishnext.htm (accessed 12 June, 2008).

Hincks, R. 2005: Computer support for learners of spoken English. Doctoral Thesis in Speech and Communication. Stockholm. Sweden.

Hincks, R. 2010: Speaking rate and information content in English lingua franca oral presentations. In English for Specific Purposes 29(1), 4-18.

Jenkins, J. 2007: English as a lingua franca. Oxford: Oxford University Press.

Johannsen, B. 2007: Attrition in university physics. A narrative study of individuals reacting to a collectivist environment. Unpublished Licentiate thesis, Uppsala University, Uppsala.

Klaassen, R. 2001: The international university curriculum: Challenges in English-medium engineering education. Doctoral Thesis, Department of Communication and Education, Delft University of Technology. Delft. The Netherlands.

Kormos, J./Dénes, M. 2004: Exploring measures and perceptions of fluency in the speech of second language learners. In System 32(145-164).

Lemke, J. 1990: Talking science: Language, learning and values. Norwood, NJ: Ablex.

Maiworm, F./Wächter, B. (eds.) 2002: English-language-taught degree programmes in European higher education, Trends and success factors. Bonn: Lemmens Verlags \& Mediengesellschaft.

Mauranen, A./Ranta, E. 2008: English as an academic lingua franca - the ELFA project.

Middendorf, J./Pace, D. 2004: Decoding the disciplines: A model for helping students learn disciplinary ways of thinking. In New directions for teaching and learning 98 (Summer 2004), 1-12.

Neville-Barton, P./Barton, B. 2005: The relationship between English language and mathematics learning for nonnative speakers. Retrieved 21 Sept. 2005 [online]. http://www.tlri.org.nz/pdfs/9211_finalreport.pdf 
Northedge, A. 2002: Organizing excursions into specialist discourse communities: A sociocultural account of university teaching. In Wells, G./Claxton, G. (eds.), Learning for life in the 21st century. Sociocultural perspectives on the future of education. Oxford: Blackwell Publishers, 252-264.

Roth, W.-M./McRobbie, C./Lucas, K./Boutonné, S. 1997: Why May Students Fail to Learn from Demonstrations? A Social Practice Perspective on Learning in Physics. In Journal of Research in Science Teaching 34(5), 509-533.

Säljö, R. 2000: Lärande i praktiken: ett sociokulturellt perspektiv [Learning in practice: a sociocultural perspective]. Stockholm: Prisma.

Seidlhofer, B. 2004: Research Perspectives on Teaching English as a Lingua Franca. In Annual Review of Applied Linguistics 24, 209-239.

Shaw, P. 2008: Engelska som lingua franca och som internationellt vetenskapsspråk [English as a lingua franca and as an international disciplinary language]. In Jansson, E. (ed.), Vetenskapsengelska - med svensk kvalitet? Stockholm: Språkrådet, 21-34.

Smit, U. 2007: ELF (English as a lingua franca) as medium of instruction - interactional repair in international hotel management education. In Dalton-Puffer, C./Smit, U. (eds.), Empirical Perspectives on CLIL classroom discourse. Frankfurt: Peter Lang, 227-252.

Towell, R./Hawkins, R./Bazergui, N. 1996: The Development of Fluency in Advanced Learners of French. In Applied Linguistics, 17(1), 84-119.

Vinke, A. 1995: English as the medium of instruction in Dutch engineering education. Delft: Department of Communication and Education, Delft University of Technology.

Wächter, B./Maiworm, F. 2008: English-taught programmes in European higher education. The picture in 2007. Bonn: Lemmens.

Wickman, P.-O./Östman, L. 2002: Learning as discourse change: A sociocultural mechanism. In Science Education 86(5), 601-623.

Östman, L. 1998: How companion meanings are expressed by science education discourse. In Roberts, D./Östman, L. (eds.), Problems of meaning in science education. New York: Teachers College Press, 54-70. 


\section{Appendix}

This appendix gives an example of the way in which texts were prepared and analyzed. The example given is for one of the four texts used for a second-year student (from case study 1).

\section{Original transcript excerpt:}

Interviewer: [...] well this is the one that he's going to change, erm, can you tell me what this, what this particular equation tells us...?

Student: $\quad$ Er, that the curl of $\mathrm{E}$ is zero, that means, er, er that the $\mathrm{E}$ is a conservative fieldvector field-it means that if you have a charged particle in an electric field and you move it in a circle or in any path and, and up it at the same point, the energy gained or lost is nothing-its, you haven't, er, er consumed or...nothing it's...so to speak.

Interviewer: So this, this curl then. Erm, what do you understand by that?

Student: $\quad$ The curl is an operation-it's a, the, the operator nabla is a partial derivatives $\mathrm{d} / \mathrm{dx}$ $\mathrm{d} / \mathrm{dy} \mathrm{d} / \mathrm{dz}$ and, er it's a, it's a vector product between the electric field which is a vector and, er the nabla which is a vector too.

First, all speech by the interviewer is deleted and marked by a double return in the transcript. The length of time the student speaks for is then calculated. Next, all noticeable pauses - both filled and unfilled - are marked by entering a single return. This creates a transcript of phrases of various lengths, each on a separate line. Then, all utterances in filled pauses - where the student uses sounds such as aah, um, er, etc - are deleted. Finally, each word in the transcript is divided up manually into syllables and a word count (effectively a syllable count) is made. The SPS value is calculated by dividing the total number of syllables in the transcript by the total student speaking time. MLR is calculated by dividing the total number of syllables in the transcript by the number of text lines (excluding empty lines). Instances of code-switching are highlighted in bold and a subjective judgement about the disciplinarity of the description is made. The results of this process on the above transcript can be seen on below

\section{Prepared transcript showing calculation and resulting values}

Time stamp, Stop: 29:22 29:49

Time stamp, Start: 28:53 29:28

Total speaking time: $29+21=50$ sec.

Total syllables: 150

Total lines: 26

SPS: $150 / 50=3.0$

MLR: $150 / 26=5.8$

Codeswitch: nil

Disciplinarity: 3-4

That the curl of $\mathrm{E}$ is ze ro

That means that the

$\mathrm{E}$ is a con serv a tive

field

vec tor field

it means that if you have a charged par ti cle in an e lec tric field

and you move it in a cir cle or in an y path and and up it at the same point

the en er gy gained or lost is noth ing

its

you have n't

con sumed or

noth ing 
it's

so to speak

the curl is an o per a tion

it's a

the

the op er a tor nab la is a

par tial de riv i tives dee dee ex dee dee wai dee dee

zee

and

it's a

it's a vec tor prod uct be tween the e lec tric field

which is a vec tor

and the

nab la which is a vec tor too 


\section{To access international literature as diverse as the study of sociology, start here.}

\section{ProQuest Sociological Abstracts offers a world of relevant,}

comprehensive, and timely bibliographic coverage. Over 890,000 easily searchable abstracts enhance discovery of full-text articles in thousands of key journals from 35 countries, along with books, conference papers, and dissertations, as well as citations to reviews of books and other media. This continuously growing collection is updated monthly, and offers backfiles to 1952 - plus scholar profiles, browsable indexes, and a searchable thesaurus through the ProQuest Illumina ${ }^{\mathrm{M}}$ interface.
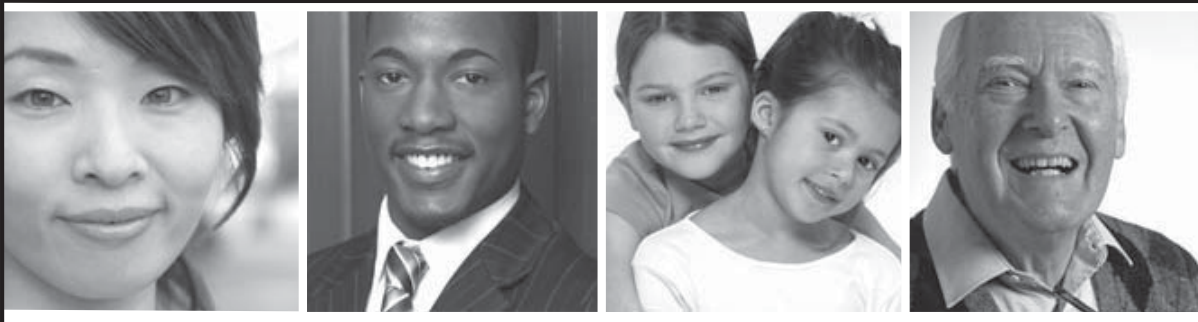

The ProQuest Sociological Abstracts Discovery Prize.

Tell us how ProQuest Sociological Abstracts has advanced teaching and learning at your institution, and you may win the ProQuest Sociological Abstracts Discovery Prize.

Visit: info.csa.com/sociologicaldiscovery

\section{ProQuest Sociological Abstracts}

For a free trial, contact pqsales@proquest.com or log onto www.proquest.com/go/csasoc today.

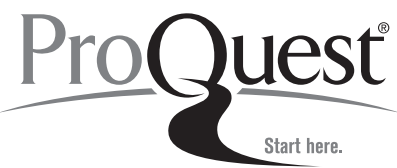

